\title{
Metallation of Shiff Bases with Ultra Disperse Ligroin Suspension of Alkali Metals and Synthesis of Diazacrown Ethers on the Basis of the Formed Metal Intermediates
}

\author{
A. L. Shabanov, M. M. Asadov, U. A. Hasanova, ${ }^{@}$ Z. O. Gahramanova, \\ and M. M. Hasanova \\ Azerbaijan State Oil Academy, RI “Geotechnological problems of oil, gas and chemistry”, Az 1010 Baku, Azerbaijan \\ ${ }^{\circledR}$ Corresponding authorE-mail: ulviyya3@rambler.ru
}

\begin{abstract}
The metallation of Shiff bases by ligroin suspension of alkali metals at the presence of crown ethers was carried out. It was found that hydrogen atoms of $\mathrm{C}$-H bonds of the methylene groups, which undergo strong mezomer effects of the phenyl and azamethyne groups, may be substituted by metals atoms. The substitution takes place at the presence of crown ethers due to the formation of alkali metal nanoanions, having extraordinary basity. On the basis of the prepared metal derivatives the diazacrown ethers were synthesized.
\end{abstract}

Keywords: Metallation, diazacrown ether, nanoanions, complexes of alkali metals with crown ethers.

\section{Металлирование Шиффовых оснований ультрадисперсной лигроиновой суспензией щелочных металлов и синтезы диазакраун-эфиров на основе образующихся металлопроизводных}

\author{
А. А. Шабанов, М. М. Асадов, У. А. Гасанова, ${ }^{@}$ 3. О. Гахраманова, \\ М. М. Гасанова
}

Научно-исследовательский институт «Геотехнологические проблемы Нефти, Газа и Химия» при Азербайджанской Государственной Нефтяной Академии, Аz 1010 Баку, Азербайджан

@Corresponding authorE-mail:ulviyya3@rambler.ru

\begin{abstract}
Проведено металлирование шиффовых оснований лигроиновой суспензией щелочных металлов в присутствии краун- эфиров. Установлено, что атомы водорода С-Н связей метиленовых групп, подвергаюшихся сильным мезомерным влияниям со стороны фенильной и азаметиновой групп, металлируются краунэфирным комплексом щелочного металла. Исходя из полученных промежуточных диметаллопроизводных синтезированы образиы диазакраун-эфиров.
\end{abstract}

Ключевые слова: Металлирование, диазакраун-эфир, наноанион, комплексы краун-эфиров с щелочными металлами.

\section{Введение}

Ранее было показано, что в присутствии краунэфиров в ультрадисперсных растворах щелочных металлов металлированию подвергаются алкилароматические углеводороды, ${ }^{[1,2]}$ приводящие к образованию их натриевых и калиевых производных. Наиболее известный классический метод металлирования ал- килароматических углеводородов, основанный на их обменной реакции с карбилами щелочных металлов, был применен с переменным успехом для углеводородов и их производных. ${ }^{[3]}$ Недостатком метода является то, что он требует предварительного приготовления дорогостоящих алкил- и арилнатрия или калия. С другой стороны, выходы часто недостаточно высоки. Данный метод представлен на ограниченном числе примеров. 
Тем не менее, следует отметить, что атомы водорода С-Н связей, ослабленные сильными мезомерными эффектами, гиперконьюгацией, индуктивными влияниями и другими факторами могут быть замещены щелочными металлами при прямом взаимодействии с предварительно приготовленными ультрадисперсными растворами щелочных металлов, содержащими краунэфиры. Способность краун-эфиров и криптандов облегчить растворение металлоорганических соединений, а также растворение щелочных металлов в органических растворителях позволяет развить новые методы прямого металлирования органических веществ..$^{[2,4-7]}$

Наиболее подходящими объектами для металлирования являются бис-шиффовые соединения, содержащие метиленовые группы, находящиеся в соседстве с кратной связью и фенильным радикалом. Эти соединения легко превращаются в диметаллопроизводные в ультрадисперсном лигроиновом растворе щелочного металла, содержащем краун-эфир в качестве катализатора. В свою очередь диметаллзамещенные бис-шиффовые основания имеют большую перспективу в синтезе оригинальных структур диазакраунсоединений. ${ }^{[8-11]}$

\section{Экспериментальная часть}

ИК спектроскопические исследования проводились на спектрометре Specord-M80 в области 4000-400 $\mathrm{cm}^{-1}$ в таблетках $\mathrm{KBr}$. ${ }^{1} \mathrm{H}$ ЯМР спектры были сняты на спектрометре Bruker-300 (300 МГц) с внутренним стандартом ТМС. Массспектры снимали на масс-спектрометре «Finniga MAT-112S» в режиме электронного удара при энергии ионизации 70 эВ и температуре источника $250^{\circ} \mathrm{C}$. В реакциях металлирования шиффовых оснований были использованы: метилбензилкетон и фенилуксусный альдегид производства компании "Fluka", дибензо-18-краун-6 и бензо-15-краун-5 производства завода химических реактивов (Черкассы). Краун эфиры очищены методом колоночной хроматографии (адсорбент $\mathrm{Al}_{2} \mathrm{O}_{3}$, элюент - хлористый метилен). Чистота очищенных краун эфиров, определенных методом электронной спектроскопии, составила $98,6 \%$ и $98,45 \%$, соответственно.

Бис-шиффовые основания II и VI были получены конденсацией метилбензилкетона и фенилуксусного альдегида, соответственно, с этилендиамином по известной методике. ${ }^{[12]}$ Индивидуальность полученных продуктов реакции установлена методом TCX на поластинке "Silufol". Элюент - эфир с гексаном, взятые в объемных соотношениях 2:1. Физико-химические и спектральные характеристики полученных бис-шиффовых оснований II и VI приведены ниже:

2,7-Диметил-3,6-диаза-1,8-дифенилокта-2,6-диен, т. кип. $173-175^{\circ} \mathrm{C} / 0,05$ мм рт.ст., $\mathrm{n}_{\mathrm{D}}{ }^{20} 1,5312$. Найдено, \%: С 81,89; Н 8,48; N 9,64. $\mathrm{C}_{20} \mathrm{H}_{24} \mathrm{~N}_{2}$. Вычислено, \%: С 82,19; Н 8,22; $\mathrm{N} 9,59$. ИК $\vee \mathrm{cm}^{-1}: 1651(\mathrm{C}=\mathrm{N}), 1457,1381 .{ }^{1} \mathrm{H}$ ЯМР $\left(\mathrm{CDCl}_{3}\right) \delta$ м.д.: 6,68-7,06 (м., 10H, Ph), 3,66 (с., 4H, $=\mathrm{N}-\mathrm{CH}_{2}-$ ), 1,1 (с., 6H, $\left.=\mathrm{C}\left(\mathrm{CH}_{3}\right)-\right), 2,62-2,35$ (м., $4 \mathrm{H},=\mathrm{NCH}_{2} \mathrm{CH}_{2} \mathrm{~N}=$ ).

3,6-Диаза-1,8-дифенилокта-2,6-диен, VI. т. кип. $167^{0} \mathrm{C} / 0,05$ мм рт.ст., $\mathrm{n}_{\mathrm{D}}{ }^{20} 1,5262$. Найдено, \%: С 81,63; Н 7,62; $\mathrm{N} 10,6 . \mathrm{C}_{18} \mathrm{H}_{20} \mathrm{~N}_{2}$. Вычислено, \%: С 81,82; Н 7,58; N 10,59. ИК v $\mathrm{CM}^{-1}: 3150-2827(\mathrm{CH}), 1649(\mathrm{C}=\mathrm{N}) 1455,1378 .{ }^{1} \mathrm{H}$ ЯMP $\left(\mathrm{CDCl}_{3}\right)$ $\delta$ м.д.: 8,15 (с., 2H, =CH-), 6,98-7,21 (м., 10H, $\mathrm{Ph}$ ), 3,58 (м., 4H, $=\mathrm{N}-\mathrm{CH}_{2}-$ ), 2,37 (м., $4 \mathrm{H},=\mathrm{NCH}_{2} \mathrm{CH}_{2} \mathrm{~N}=$ ).

Приготовление ультрадисперсных лигроиновых растворов щелочных металлов в присутствии краун эфиров. $\mathrm{B}$ металлическом реакторе, изготовленном из нержавеющей стали, снабженном рубашкой для нагревания и охлаждения и высокоскоростной мешалкой (10000 об./мин.), поместили мелкораздробленный натрий $(11,5$ г, 0,5 моль) в 100 мл лигроина, затем воздух вытеснили из реактора азотом. К реакционной смеси в реакторе добавили бензо- 15 -краун-5 $(13,4$ г, 0,05 моль). Реакционную массу нагревали до расплавления металического натрия и перемешивали в течение 1,5-2 мин. Затем полученную ультрадисперсную сиситему охладили до $23^{\circ} \mathrm{C}$.

По аналогичной методике был приготовлен ультрадиперсный лигроиновый раствор, исходя из дибензо18-краун-6 и металлического калия.

Металлирование Шиффового основания II и замыкание его в макрочиклическое соединение IV. K раствору соединения II (14,6 г, 0,05 моль) в 150 мл лигроина прибавили бензо-15-краун-5 (2,1 г, 0,0125 моль). Реакционную смесь перемешивали при температуре $25-27^{\circ} \mathrm{C}$ до растворения краун-эфира и шиффового основания. Все операции проводились в атмосфере инертного газа азота. Затем к раствору при энергичном перемешивании и охлаждении (температура среды $8-9^{\circ} \mathrm{C}$ ) осторожно прибавляли по порциям предварительно приготовленный ультрадисперсный лигроиновый раствор, содержащий 2,07 г (0,09 моль) натрия. К концу реакции температура среды оставалась неизменной. После прибавления всего количества ультрадисперсного раствора натрия, реакционную смесь разбавили 800 мл лигроина и нагревали до комнатной температуры. Затем добавили при перемешивании по каплям 1,5-дибром3 -оксапентан (11,6 г, 0,05 моль) в 50 мл лигроина. После прибавления всего количества дибромэфира реакционную смесь кипятили в течение 24 часов. После удаления бромистого натрия фильтрованием и лигроина под вакуумом остаток экстрагировали кипящим октаном $(5 \times 40$ мл)

Гидрирование октанового экстракта. К октановому экстракту добавили предварительно приготовленное количество никеля Ренея, полученного из 3,0 г никельалюминиевого сплава, реакционный сосуд подключили к водородному баллону и через экстракт, нагретый до $60^{\circ} \mathrm{C}$, пропускали при перемешивании водород под давлением 2,5 МПа. К концу реакции поглощения водорода не наблюдалось. По окончании реакции никель Ренея отделили фильтрованием, из фильтрата под вакуумом удалили октан, черно-коричневый остаток растворили в спирте. При стоянии выпали 3,25 г (17,6 \%) маслянистых кристаллов макроциклического соединения $\mathbf{V}$, которые при повторной кристаллизации из $н$-октана имели температуру плавления $87^{\circ} \mathrm{C}$. Найдено \%: С 78,49; Н 9,34; N 7,43. $\mathrm{C}_{24} \mathrm{H}_{34} \mathrm{~N}_{2} \mathrm{O}$. Вычислено \%: С 78,68; Н 9,28; N 7,65. Массспектр: 365. ИК $v \mathrm{~cm}^{-1}: 3300(\mathrm{NH}), 2983-2807(\mathrm{CH}), 1457,1382$, 1138, 723; 1112, 1250 (С-О-С). ' $\mathrm{H}$ ЯМР $\left(\mathrm{CDCl}_{3}\right) \delta$ м.д.: 2,68-2,48 (м., $\left.8 \mathrm{H}, \mathrm{CH}\left(\mathrm{CH}_{3}\right) \mathrm{NHCH}_{2} \mathrm{CH}_{2} \mathrm{NHCH}\left(\mathrm{CH}_{3}\right)\right), 3,25$ (м., 4H, $\mathrm{CH}_{2}-\mathrm{O}-$ $\mathrm{CH}_{2}$ ), 1,6-1,21 (м., 6H, $\mathrm{CH}_{2} \mathrm{CHPh}$ ), 7,2-6,68 (с., 10H, $\mathrm{Ph}$ ), 1,25 (c., $\left.6 \mathrm{H}, 2 \mathrm{CH}_{3}\right)$.

Металлирование Шиффового основания VI и замыкание его в макрочиклическое соединение VIII. К раствору 1,8-дифенил-3,6-диазаоктадиена-2,6 (13,2 г, 0,05 моль) в 150 мл лигроина прибавили 4,5 г (0,0125 моль) дибензо-18-краун-6. Реакционную смесь перемешивали при температуре $25-27^{\circ} \mathrm{C}$ до растворения краун-эфира и шиффового основания. Все операции проводились в атмосфере азота. Затем к раствору при энергичном перемешивании и охлаждении (температура среды 5-6 ${ }^{0}$ ) осторожно прибавляли отдельные порции предварительноприготовленнойультрадисперсной суспензии 3,51 г (0,09 моль) калия в лигроине. После прибавления всего количества калия, реакционную смесь разбавили 800 мл лигроина и нагревали до комнатной температуры. Затем добавили при перемешивании по каплям раствор 1,5-дибром3 -оксапентана (11,6 г, 0,05 моль) в 50 мл лигроина. После прибавления всего количества дибромэфира реакционную 
смесь кипятили в течение 24 часов. Конец реакции установили методом ТСХ по исчезновению дибромэфира. Калий бромистый отделили фильтрованием и после удаления лигроина под вакуумом остаток экстрагировали кипящим октаном (5×40 мл)

Гидрирование октанового экстракта. К октановому экстракту добавили предварительно приготовленное количество никеля Ренея, полученного из 3,0 г никельалюминиевого сплава, реакционный сосуд подключили к водородному баллону и через экстракт, нагретый до $60^{\circ} \mathrm{C}$, пропускали при перемешивании водород, под давлением 2,5 МПа. К концу реакции поглощения водорода не наблюдалось. По окончании реакции никель Ренея отделили фильтрованием, из фильтрата под вакуумом удалили октан, черно-коричневый остаток растворили в спирте. При стоянии выпали белые кристаллы макроциклического соединения IX (3,1 г, 19,2 \%), которые при повторной кристаллизации из $H$-октана имели температуру плавления $82^{\circ} \mathrm{C}$. Найдено \%: С 78,29; Н 9,04; N 8,43. $\mathrm{C}_{22} \mathrm{H}_{30} \mathrm{~N}_{2} \mathrm{O}$. Вычислено \%: С 78,1; Н 8,87; N 8,28. Масс-спектр: 337. ИК $v$ см$^{-1}: 3295(\mathrm{NH}), 2977-2822$ $(\mathrm{CH}), 1376,1129,712,1100$ и 1247 (C-O-C). ${ }^{1} \mathrm{H}$ ЯMР $\left(\mathrm{CDCl}_{3}\right) \delta$ м.д.: 2,75-2,46 (м., $10 \mathrm{H}, 2 \mathrm{CH}_{2} \mathrm{NHCH}_{2}$ ), 3,3 (м., 4H, $\mathrm{CH}_{2}-\mathrm{O}-\mathrm{CH}_{2}$ ), 2,2 (с., 2Н, СН), 7,1-6,9 (с., 10H, 2Ph). Потенциометрическим титрованием этого соединения стандартным раствором $\mathrm{HCl}$ также подтверждается наличие двух аминных групп.

Чистота и индивидуальность синтезированных краунсоединений $\mathbf{V}$ и IX определена методом TCX на пластинке Silufol (элюент - эфир с $н$-гексаном 2:1).

\section{Обсуждение результатов}

Ранее нами было установлено, что при растворении щелочных металлов в органических растворителях в присутствии краун-эфиров или криптандов образуется полигомометаллический наноанион $\mathrm{M}_{\mathrm{n}}-\mathbf{I}$, который находится вне полости макроциклического лиганда. ${ }^{[1,2,13]}$ Однако при растворении щелочных металлов в основных растворителях, таких как этилендиамин, диалки- ламин и др. получается комплексное соединение IA, содержащее монометаллический анион, находящийся вне полости макроциклического кольца. Количество анионов щелочного металла в комплексах I и IA установлено волюмометрическим методом, предложенным в работе ${ }^{[14]}$.

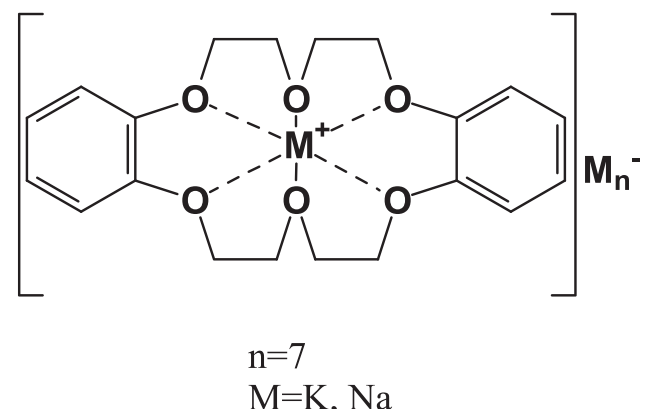

I
$\left[\mathrm{KЭЭM}^{+}\right] \mathrm{M}^{-}$

$\mathrm{M}=\mathrm{K}, \mathrm{Na}$
Сущность процесса образования таких систем при помощи краун-соединений заключается в том, что макроциклический лиганд при температурах ниже $0^{\circ} \mathrm{C}$, выбивая из кристаллической решетки катион щелочного металла, образует комплексные соединения [КЭ· $\left.\mathrm{M}^{+}\right]$ $\mathrm{M}_{\mathrm{n}}$, $^{[1]}$ в которых $\mathrm{M}_{\mathrm{n}}$ - является гомополиметаллид анионом. Дальнейшие исследования, проведенные нами ${ }^{[12]}$ показали, что при этом образуются комплексные соединения состава $\left[\mathrm{KЭ}^{\circ} \mathrm{M}^{+}\right] \mathrm{M}_{7}^{-},{ }^{[1,2]}$ в которых металлид анион $\mathrm{M}_{7}^{-}$является наночастицей. Учитывая высокую основность этих металлид анионов ${ }^{[14]}$ нами было осуществлено прямое металлирование органических соединений, содержащих два шиффовых фрагмента. Такие соединения имеют большую перспективу для конструирования диазакраун-эфиров, поскольку<smiles>[R]C(Cc1ccccc1)=NC</smiles>

I: $\mathrm{R}=\mathrm{CH}_{3}$ VI: $\mathrm{R}=\mathrm{H}$

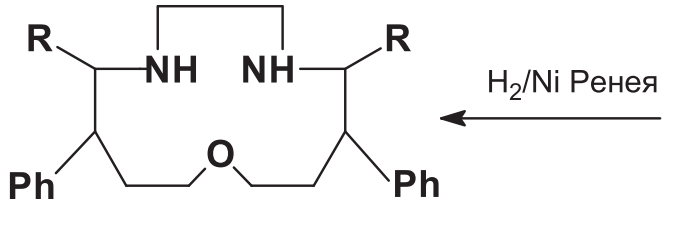

V: $\mathrm{R}=\mathrm{CH}_{3}$ IX: $\mathrm{R}=\mathrm{H}$<smiles>[R]C(=NCCN1CCCC1)C([M])c1ccccc1</smiles>

III: $\mathrm{R}=\mathrm{CH}_{3} ; \mathrm{M}=\mathrm{Na}$

VII: $\mathrm{R}=\mathrm{H} ; \mathrm{M}=\mathrm{K}$<smiles>CCCOCCBr</smiles>

IV: $\mathrm{R}=\mathrm{CH}_{3}$

VIII: $\mathrm{R}=\mathrm{H}$ 
метиленовые водороды, находящиеся между двумя сильными мезомерными группами $(\mathrm{Ph},-\mathrm{N}=\mathrm{C}<)$, могут замещаться атомами щелочных металлов, при взаимодействии с предварительно приготовленной лигроиновой суспензией наночастиц щелочных металлов ${ }^{[2,14]}$ В присутствии макроциклических соединений. Благодаря исключительной высокой основности полигомометалиического аниона $\mathrm{M}_{\mathrm{n}}^{-}$шиффовые основания II и VI, реагируя с краун-эфирным комплексом щелочного металла I, образуют соответствующие диметалопроизводные III и VII. Реакция проводится в 5\%-ном избытке Шиффового основания, который обеспечивает полный расход щелочного металла в лигроине.

Для осуществления замыкания полученных промежуточных диметаллопроизводных шиффовых оснований III и VII с 2,2'-дибромэтиловым эфиром в соответствующие макрогетероциклы IV и VIII, реакционная смесь разбавляется лигроином до $5 \times 10^{-2}$ моль/л по взятому шиффовому основанию и добавляется порциями эквивалентное количество дибромэфира при кипячении и перемешивании. По окончании реакции после удаления лигроина из сложной смеси маслянистого кристаллического остатка не удавалось выделить кристаллы чистых образцов макрогетероциклов IV и VIII кристаллизацией. По данным ТСX определения на пластинке Silufol (элюент эфир с $н$-гексаном 2:1) обнаружено наличие по меньшей мере четырех компонентов. Для выделения макрогетероцикла из этой смеси нами использован метод селективной экстракции $\boldsymbol{H}$-октаном. Затем каталитическим гидрированием октанового экстракта были получены с выходами 17,6\% и 19,2\% диазакраун-эфиры V и $\mathbf{I X}$, соответственно.

Строение полученных краун-соединений $\mathbf{V}$ и $\mathbf{I X}$ установлено на основании данных элементного анализа, определения молекулярной массы и изучением ИК и ЯМР спектров.

\section{Выводы}

Для введения атомов щелочных металлов в бензильные положения металлирование шиффовых оснований II и VI осуществлено с применением ультрадисперсных лигроиновых растворов щелочных металлов в присутствии краун-эфиров. Показано, что в металлировании участвует полигомометаллический наноанион щелочного металла $\mathrm{M}_{\mathrm{n}}^{-}$. Сущность процесса образования таких систем при помощи краунсоединений заключается в том, что макроциклический лиганд при температурах ниже $0^{\circ} \mathrm{C}$, выбивая из кристаллической решетки катион щелочного металла, образует комплексные соединения [KЭ· $\left.\mathrm{M}^{+}\right] \mathrm{M}_{\mathrm{n}}^{-}$, в которых металлид анион $\mathrm{M}_{\mathrm{n}}^{-}$является наночастицей. Учитывая высокую основность этих металлид анионов нами было осуществлено прямое металлирование органических соединений, содержащих два шиффовых фрагмента. Показано, что металлированию подвергаются метиленовые группы, находящиеся между фенильной группой и кратной связью. Метиленовые группы, находящиеся между двумя атомами азота, не металлируются.

Установлено, что наиболее подходящими оптимальными структурами краун-эфиров для металлирования калием и натрием являются дибензо-18-краун-6 и бензо-15-краун-5, соответственно. Образующиеся при этом диметаллопроизводные III и VII при взаимодействии с 2,2'-дибромэтиловым эфиром замыкаются в соответствующие макрогетероциклические соединения IV и VIII, которые при дальнейшем гидрировании с применением никеля Ренея в качестве катализатора превращаются в соответствующие диазакраун-соединения V и IX с выходами 17,6\% и 19,2\%, соответственно.

\section{Список литературы}

\section{References}

1. Shabanov A.L., Ramazanova E.E., Hasanova U.A. Trudi NII "Geotekhnologicheskie Problemi Nefti i Gaza" Azerbaijan State Oil Academy 2006, 8, 356 (in Russ.).

2. Shabanov A.L., Hasanova U.A. Kakhramanova Z.O., Hasanova M.M. Azerb. Khim. Zh. 2006, 3, 166 (in Russ.).

3. Talalaeva T.V., Kocheahkov K.A. Metody Elementorganicheskoi Khimii [The Methods of Elemenorganic Chemistry] Moskva: Nauka, 1971. 1192 p. (in Russ.).

4. Mei Tak Lok, Tehan F. J., Due J. L. J. Phys. Chem. 1972, 76, 2975.

5. Down J.L., Lewis J., Moore B., Wilkinson G. J. Chem. Soc 1959, 3767.

6. Dye J.L., Debacker M.G., Nicely V.A. J. Am. Chem. Soc. 1970, 92, 5226.

7. Sergeev G.B. Nanokhimiya [Nanochemistry] Moskva: MGU, 2003. 287 p. (in Russ.).

8. Cherkasov V.M. Boldyrev I.V. Khim. Getrotsikl. Soed. 1998, 34, 749-761 (in Russ.).

9. Bradshaw J.S., Krakowiak K.E., Izatt R.M. Aza-Crown Macrocycles. New York: Wiley, 1993. p. 51.

10. Gersch B., Lehn J.-M., Grell E. Tetrahedron Lett. 1996, 37, 2213-2216.

11. Kocian O., Spencer N., Stoddart J.F., Cragg-Hine I., Davidson M., Mair F.S., Raithby P., Snaith R., Kottked T., Pohl E. Tetrahedron 1995, 51, 579-590.

12. Mamedova Sh.M. Diss. Cand. Chem. Sci. NANA Baku 2001 112 p. (in Russ.).

13. Shabanov A.L., Seidov N.M., Gakhramanova Z.O., Hasanova U.A., Hasanova M.M. Zh. Org. Khim. 2009, 45, 33-37 (in Russ.).

14. Shabanov A.L. In: The 10th Annual Florida Heterocyclic and Synthetic Conference. ARCAT USA, 2009, p.48.

Received 02.04.2010

Accepted 31.08.2010

First published on the web 27.09.2010 